\title{
How Safe Are Radiation Doses in Diagnostic Radiology? A Historical Perspective and Review of Current Evidence
}

\author{
Srikanth Moorthy ${ }^{10}$ \\ ${ }^{1}$ Department of Radiology, Amrita Institute of Medical Sciences and \\ Research Centre, Amrita School of Medicine, Amrita Vishwa \\ Vidyapeetham, Amrita Lane, Ponekkara, Kochi, Kerala, India \\ Indian J Radiol Imaging 2021;31:653-660.
}

\begin{abstract}
Address for correspondence Srikanth Moorthy, MD, Department of Radiology, Amrita Institute of Medical Sciences and Research Centre, Amrita Vishwa Vidyapeetham, Amrita Lane, Ponekkara, AIMS P.O., Kochi, Kerala 682041, India

(e-mail: jyothisri@gmail.com; smoorthy@aims.amrita.edu).
\end{abstract}

\begin{abstract}
Keywords

- radiation

- dose

- radiology

- safety

- history
\end{abstract}

\section{Introduction}

"Nothing in life is to be feared, it is only to be understood"Marie Curie

The risks of radiation have been an ever-present concern for radiation workers since the discovery of $\mathrm{X}$-rays and radioactivity at the end of the 19th century. After the atomic bombing of Hiroshima and Nagasaki, this concern flooded the public conscience and as a consequence, governments and regulatory agencies adopted a sort of zero tolerance to radiation risks in the form of the Linear no-threshold (LNT) model. Since then, meticulous follow-up of the atom bomb survivors, early radiobiological studies, and the sensational nuclear accidents in Chernobyl and Fukushima had reinforced this concern and the desire for absolute safety. Routine radiation doses to patients, medical staff, and industrial radiation workers are below $100 \mathrm{mGy}$. With rare exceptions, populations exposed to high environmental radiation from natural sources or contamination following accidents also fall in this dose range. In other words, risks of low dose radiation, encountered in the process of peaceful application of radiation, are more relevant to society. Incontrovertible evidence exists for stochastic effects at doses above 0.5 to 1 Gy. The LNT model, however, extrapolates this risk linearly into the low dose range all the way to zero. Paradoxically recent data from these very same sources-population studies and radiobiology-which established and validated the LNT model over the years, have yielded evidence which casts doubt on this assumption. These developments have great import to both the future of radiology practice and nuclear power. Recently studies claiming increased risk of cancer
DOI https://doi.org/ 10.1055/s-0041-1735927. ISSN 0971-3026.

\footnotetext{
(C) 2021. Indian Radiological Association. All rights reserved. This is an open access article published by Thieme under the terms of the Creative Commons Attribution-NonDerivative-NonCommercial-License, permitting copying and reproduction so long as the original work is given appropriate credit. Contents may not be used for commercial purposes, or adapted, remixed, transformed or built upon. (https://creativecommons.org/ licenses/by-nc-nd/4.0/)

Thieme Medical and Scientific Publishers Pvt. Ltd., A-12, 2nd Floor, Sector 2, Noida-201301 UP, India
} 
from CT scanners have created a furore both among the public as well as within the medical community. It is vital that radiologists are aware of the origin and evolution of concepts of radiation risk and the emerging evidence indicating safety of low dose radiation.

The discovery of X-rays in 1895 was followed by its wide and rapid adoption for various applications ranging from research in the physical sciences to medical diagnosis to cosmetic skin treatments and even shoe-fitting fluoroscopes. Radioactivity discovered a year later was also subject to intense investigation by scientists and found early commercial applications like radium dials in watches. Along with this enthusiasm and the obvious benefits, the risks of radiation also became apparent within a few years. The tragic story of Clarence Dally, Thomas Alva Edison's assistant, is a case in point. Dally was involved in developing an improved X-ray tube which involved long hours of exposure to radiation to his hands without any protection. He developed radiation burns on both hands which subsequently became cancerous and had to undergo a series of amputations of both upper limbs before succumbing to metastatic disease. ${ }^{1}$ Subsequently many physicists and medical imaging pioneers in the western world also suffered injuries and some of them, unfortunately, became radiation "martyrs." Though the mechanism of injury was not known, knowledge of the physics of X-rays and gamma rays itself led to early protection measures based on time of exposure, distance, and shielding. However, up until the middle of the $20^{\text {th }}$ century, radiation effects on the body remained largely in the domain of experts and was not a cause for public concern.

In 1927, Herman J. Mueller, discovered that X-rays produce mutations in the germ cells of Drosophila fruit fly by observing anomalies in the progeny. ${ }^{2}$ The discovery, apart from illuminating and opening new avenues in the field of genetics, marked the first step in the study of biologic effects of radiation. In 1928, the International X-ray and Radium Protection Committee (IXRPC) was established with Rolf Maximilian Sievert as chairman. The organization was renamed International Committee for Radiological Protection (ICRP) in $1950 .^{3}$ The Americans constituted the National Council on Radiation Protection \& Measurements (NCRP) in 1929. In 1934 IXRPC recommended a "tolerance" dose of 0.2 Roentgens per day (approximately $730 \mathrm{mSv} / \mathrm{y}$ ) for radiation workers. The term "tolerance" implies that there are no risks below that threshold dose. In 1951, amidst mounting concerns about effects of radiation this was revised down to 0.3 Roentgens per week (approximately $154 \mathrm{mSv} / \mathrm{y}$ ) and the term "maximum permissible" dose was applied implying uncertainty about absolute safety below this level. ${ }^{4}$

The atom bombing of Hiroshima and Nagasaki in August 1945 and its immediate aftermath shocked the scientific world and the general public, forcefully bringing into center stage the danger posed by nuclear weapons and more importantly, the hazards of radiation to public health. Herman Mueller in his Nobel Prize acceptance speech in 1946 stated that dose-injury relationship for mutations was linear and that no dose, however, small, is safe. ${ }^{5}$ In the 1950 s the United States (U.S.), Britain and Union of Soviet Socialist
Republics (USSR) conducted hundreds of surface-based and high atmosphere nuclear tests leading to significant radioactive fallout. Despite government secrecy and official assurances that the radiation levels were within safe limits, there was great public anxiety and scientists like Linus Pauling campaigned for banning atmospheric nuclear tests. It is important to understand that germline genetic modification by radiation-induced mutations which could potentially harm millions of unborn children was the dominant concern of this era. Somatic effects like cancer were thought to have a different mechanism. ${ }^{4,5}$ The geneticists argued that the same risk of radiation-induced mutations in germ cells must apply to somatic cells and further that these mutations could lead to cancer. Thus, the basis of carcinogenesis that we today accept as fact was first expressed in the nuclear safety debate of the 1950s. The deoxyribonucleic acid (DNA) structure had just been discovered by Watson and Crick in 1953 and it would take many years to unravel the gene as a physical entity and understand its function in cells. The "no safe dose" was proposed based on germline mutations for which the geneticists apparently had direct evidence. This also made the gonads appear to be the most critical targets of radiation, a fact that was to have a very long-lasting impact on regulatory policy and the perceptions of generations of doctors and patients.

\section{Linear No-Threshold Model}

Recent research has shown that there were other dose response studies at that time that suggested a linear relationship only at high doses raising the possibility of a threshold effect. But these studies were overlooked by dominant voices including Mueller, due, perhaps, to their strong moral indignation at the use of atomic science for war and their desire to protect future generations from potential harm. ${ }^{5}$ In view of the raging controversy playing out in the media and scientific circles the U.S. National Academy of Sciences constituted a Biological Effects of Atomic Radiation (BEAR) committee to study the issue and provide recommendations. The $1^{\text {st }}$ BEAR report submitted in 1956 recommended reductions in permissible dose and adoption of LNT model for guiding regulatory policy. Later the committee was renamed Biological Effects of Ionizing Radiation (BEIR) and it has continued to submit its recommendations periodically, the latest being the BEIR VII report in 2006. By the early 1970s the LNT model was firmly established and adopted by ICRP and all other national regulatory bodies. The recommendation of the ICRP Publication No: 26 adopted in 1977 was a watershed in radiation safety history. ${ }^{6}$ It outlined for the first time the ALARA (as low as reasonably achievable) principle which follows directly from the LNT concept and became central to the practice of Radiology. The publication also, for the first time, assigned tissue weighting factors for various organs based on their estimated sensitivity to radiation injury.

The linear no threshold model underpins the radiation safety recommendations and cancer risk predictions of international and national radiation safety authorities- 


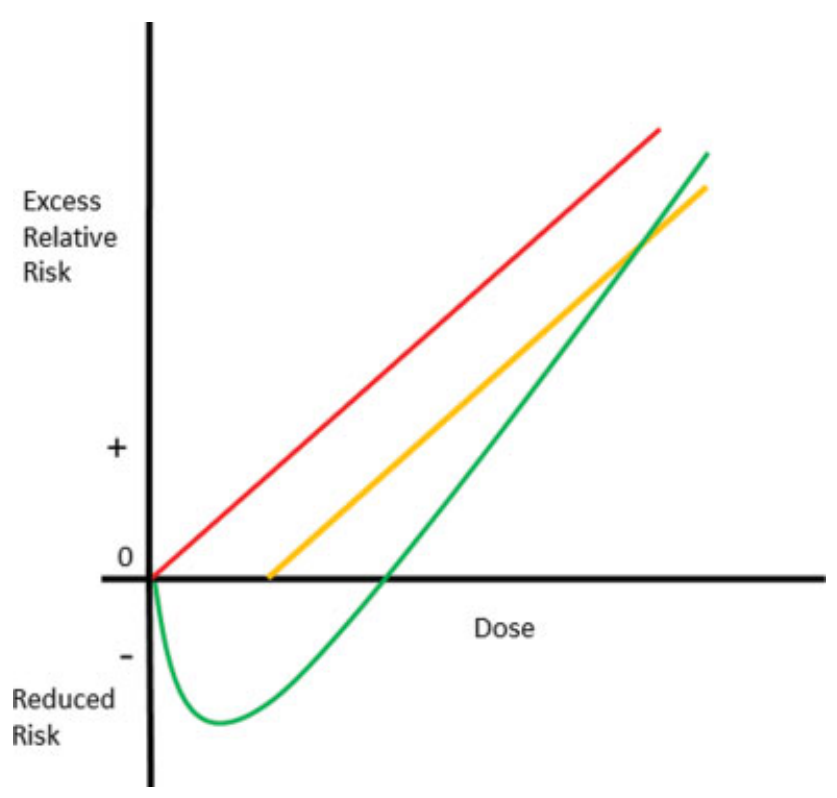

Fig. 1 Schematic graphs showing three dose responses. Linear nothreshold (red) is a straight line, starts at zero and has no curve. Threshold response (yellow) rises from a threshold dose after zero. Hormetic curve ( $g r e e n)$ is biphasic. At low doses it dips below baseline, indicating benefit and then crosses baseline at a threshold and rises into the zone of risk. All three responses are considered plausible in radiobiology.

ICRP, NCRP, Atomic Energy Regulatory Board (AERB), United Nations Scientific Committee on the Effects of Atomic Radiation (UNSCEAR), etc. The model is based on a "single-hit" hypothesis which assumes that a photon or particle of ionizing radiation directly damages a random part of the DNA molecule leading to a point mutation or strand break which can turn into cancer later on or, in the case germ cells, cause congenital anomalies in the progeny. LNT implies that even the smallest incremental dose above background increases the relative risk for oncogenesis by a proportional amount and that damage is cumulative ( - Fig. 1 ). The LNT model and the ALARA principle find application not only in medical procedures but also directs the design, construction, and operation of nuclear power plants. Nuclear waste disposal and government policy related to the evacuation of public and environmental clean ups following nuclear accidents are also guided by this concept.

\section{Is LNT Model Reliable for Low Dose Exposures?}

While the link between radiation and cancer at high doses above $1 \mathrm{~Gy}(1,000 \mathrm{mGy})$ is unquestionable, at lower doses there is room for skepticism. By convention "Low Dose" refers to doses below $100 \mathrm{mSv}$. This is the range which concerns patients undergoing diagnostic radiology procedures, radiation workers, and populations exposed to natural radiation or contamination of environment. Though the model is universally accepted and applied for regulatory purposes, many physicists and even some scientific bodies have questioned its validity in recent times. The reasons for this shift in thinking have arisen from different parts of the world and in different fields of study. It is necessary for radiologists to be acquainted with these issues to have a holistic and updated understanding of radiation safety in their practice. There are five distinct "stories": (1) Data from the atom bomb survivor Life Span study; (2) The recent CT radiation dose controversy; (3) Molecular biological studies on the response of cell and DNA to radiation; (4) Studies of populations exposed to high levels of natural and background radiation in India, China, Brazil, and Iran and (5) Studies of the local population and environment in Chernobyl and Fukushima. We will examine each one in turn.

\section{The Life Span Study}

After the atomic bombing of Hiroshima and Nagasaki, the Japanese and the U.S. governments collaborated to study the effects of radiation on the surviving population in these cities. In 1947, the Atom Bomb Casualty Commission was created to oversee and coordinate the effort to identify survivors, conduct clinical examinations, and collect data. In 1955 ABCC launched the Life Span Study (LSS) which is a multicohort lifelong follow-up of atom bomb survivors and controls. In 1975, the commission was renamed as the Radiation Effects Research Foundation (RERF). The LSS remains, to this day, the most important source for our understanding the effects of radiation on humans. All the radiation risk assessment and safety recommendations of the ICRP and the various national organizations derive from the LSS results which are published from time to time.

The main cohort of the LSS was the carefully selected 120,000 residents of Hiroshima and Nagasaki, 96,000 of whom were exposed to the bomb and 24,000 were controls who were "not in city" at the time of the bombing. The dose to each survivor was estimated by ascertaining the distance from the center to the spot where the person found herself at the time of bombing and the shielding present, i.e., whether the person was in the open or inside a wooden/metal/ concrete building or underground in a shelter. It is noteworthy that though the mean dose was $200 \mathrm{mSv}, 80 \%$ of subjects in the study received doses less than $100 \mathrm{mSv}$ and only $7 \%$ received doses above $500 \mathrm{mSv}$. The second cohort was 3,600 women pregnant and exposed at the time of bombing and followed up to study the effect of radiation in utero. The third cohort was 77,000 children whose one parent or both parents were survivors of the bombing.

The risk for cancer is expressed as excess relative risk (ERR). Relative risk is the ratio of occurrence rate in exposed population to that in controls, i.e., number of cancers in exposed individuals/number of exposed individuals divided by number of cancers in nonexposed/number of nonexposed individuals. ERR is this value minus 1.

Increased risk for leukemia became evident by the early 1950 s in subjects who received more than approximately $200 \mathrm{mSv}$. The incidence peaked early and reduced over the years with the majority of excess deaths occurring before 1975. There were $45 \%$ excess deaths in those exposed to more than $5 \mathrm{mGy}$ and $86 \%$ more for those exposed to $1 \mathrm{~Gy}$. However, leukemia is a rare disease, and the absolute 
number of excess deaths was only 98 and it was seen predominantly in persons exposed at a young age.

Solid cancers on the other hand had a long latency and showed a gradual increase which remained proportional to age-related cancer rates of the nonexposed population. The highest ERR ( $>0.8$ ) was observed for bladder, female breast, and lung cancers. However, the largest absolute number of excess cancers was seen for female breast, stomach, colon, lung, and liver cancers due to the high incidence of these cancers in the Japanese population. It is worth noting that out of a total of 17,448 cancers detected in the entire cohort of 120,000 subjects, there were only 853 cancers which were attributable (excess over baseline rate) to radiation. This represents just $11 \%$ of all subjects exposed to $>5 \mathrm{mGy}$ who developed solid cancers. This proportion increases to nearly $50 \%$ in subjects who received $>1 \mathrm{~Gy}$, $^{7,8}$

Based on the data LSS had postulated a linear dose response from low doses ( $<100 \mathrm{mGy}$ ) all the way to $2 \mathrm{~Gy}$. Most recent analysis of the LSS data reveals a very small ERR of 0.01 in the 0 to $100 \mathrm{mSv}$ range and the investigators advice caution in attributing causation to radiation below $100 \mathrm{mSv} .^{9}$ Significantly, females have a 50\% more excess risk than males and a steeper and more linear response at all dose ranges. Younger age at exposure and higher attained age (time from exposure to cancer) increases the risk significantly. The overall life span of survivors was reduced by 1.3 year for an exposure of $1 \mathrm{~Gy}$ and by only 1 month, on an average, for an exposure of $100 \mathrm{mSv}{ }^{10}$

To put it in perspective an acute exposure of $1,000 \mathrm{mGy}$ to a population of 100 people would lead to one excess cancer over and above the 42 persons who would have cancer from other causes. ${ }^{11}$ The natural background rate of cancer in humans is very high-around $40 \%$ in males and $29 \%$ in females. Detecting a very small increase, if any, of cancer in a population exposed to low doses of radiation is a big epidemiological challenge. There is, thus, reason to doubt the validity of extrapolating risks at high doses to doses below 200 or $100 \mathrm{mGy}^{12}$ (-Fig. 2).

The in utero exposure cohort showed significant mental retardation of children in those exposed between 8 and 15 weeks post conception. This manifested as microcephaly, neuronal migration anomalies, or abnormal brain architecture. A threshold of more than $300 \mathrm{mGy}$ was observed. No effects were seen for exposures before 8 weeks or after 25 weeks. The risk for leukemia and solid cancers for in utero exposure was slightly less than that for exposure in childhood. $^{7}$ The ICRP 84 publication which laid down recommendations for radiation safety in pregnancy reflect these findings. Risk for mental retardation and other congenital anomalies is deemed to be minimal or nonexistent even at fetal exposures of $100 \mathrm{mSv}$ which are extremely unlikely in diagnostic radiology. ${ }^{13}$ Radiologists need to be aware, that not doing an indicated abdominal CT (10$20 \mathrm{mSv}$ ) for an emergent indication in a pregnant woman may not be appropriate or wise and that there is no rationale for termination of pregnancy following an indicated or accidental exposure to diagnostic X-rays in pregnancy.

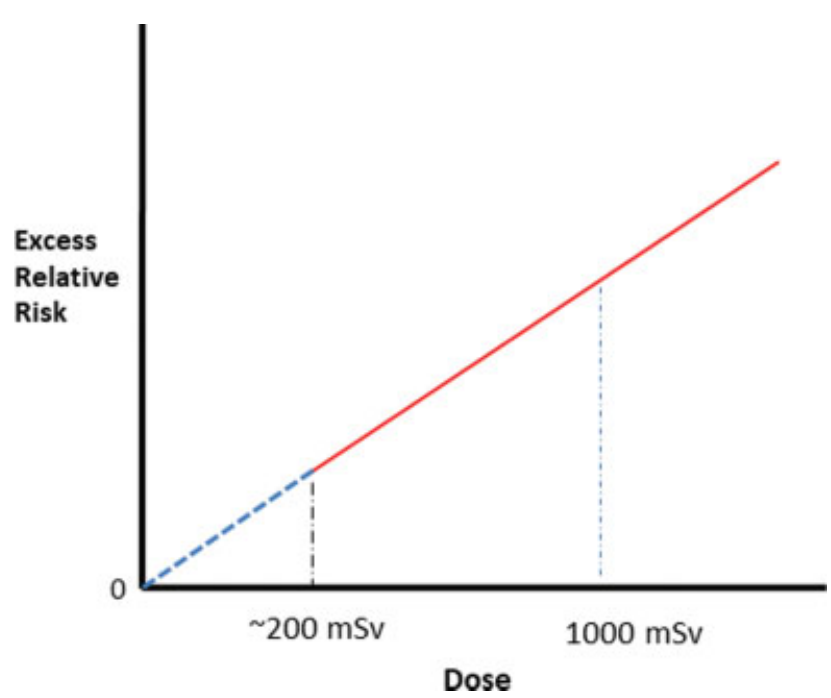

Fig. 2 Schematic graph showing linear dose response to radiation at high doses (solid line) with strong evidence and extrapolation of this trend to low doses (dashed line) where the risk is difficult to establish over background cancer rates.

The third LSS cohort of children born to exposed parents was carefully selected to address the most important question the scientific community was facing in the 1950s-the effect of radiation on germ cells and thereby the next generation. The surprising finding was that irrespective of the amount of radiation received by one or both parents, there was no excess incidence of congenital anomalies, mental retardation, or childhood leukemia. Some of these individuals are in their 7th decade of life now and there has also been no increase in adult cancers compared with controls. Even direct tests for chromosomal aberrations in peripheral leukocytes do not show any difference. ${ }^{7}$ The relative radio-resistance of human germ cells, evident by the 1990s, upturned a long-held dogma and effectively took the gonads out of the center of the radiation safety debate. However, "gonad centricity" continues to cast a shadow over training in radiodiagnosis and our choice of subspecialty practice! Comparing the relative weights assigned to various organs in the ICRP tissue weighting tables over the years is very instructive ( $\mathbf{-}$ Table $\mathbf{1}$ ). In the very first publication (ICRP 26 in 1977), the gonads were assigned $25 \%$ of the total risk to all tissues. This was reduced to $20 \%$ in the second publication (ICRP 60 in 1990) and dramatically scaled down to $8 \%$ in the latest update (ICRP 103 in 2007). ${ }^{6,14}$

\section{Recent Radiation Controversies in Diagnostic Radiology}

In 2007 Brenner and Hall published an article in New England Journal of Medicine (NEJM) highlighting the exponential increase in radiation to the American public, over the preceding decade, from medical procedures, especially CT scans. ${ }^{15}$ Brenner and Hall estimated the collective dose from all radiological investigations and divided that figure by the U.S. population to derive an average excess dose per person per year of $3 \mathrm{mSv}$ from medical procedures alone. The 
Table 1 The evolution of ICRP tissue weighting factors over three decades

\begin{tabular}{|l|l|l|l|}
\hline Organs & ICRP 26 & ICRP 60 & ICRP 103 \\
\hline Gonads & 0.25 & 0.20 & 0.08 \\
\hline Breast & 0.15 & 0.05 & 0.12 \\
\hline Red marrow & 0.12 & 0.12 & 0.12 \\
\hline Lung & 0.12 & 0.12 & 0.12 \\
\hline Thyroid & 0.03 & 0.05 & 0.04 \\
\hline Colon & - & 0.12 & 0.12 \\
\hline Stomach & - & 0.12 & 0.12 \\
\hline Esophagus & - & 0.05 & 0.04 \\
\hline Liver & - & 0.05 & 0.04 \\
\hline Brain & - & - & 0.01 \\
\hline Skin & - & 0.01 & 0.01 \\
\hline Remainder & 0.30 & 0.05 & 0.12 \\
\hline
\end{tabular}

Note: Note reduction in values for gonads and the increases for breast, stomach, and colon.

collective dose when multiplied by the slope of the LNT line derived from LSS can give the total excess cancer deaths that can be expected. The authors stated that up to $2 \%$ of all cancers in the United States may be attributable to radiation from CT. Ironically the ICRP publication 103 in the same year clearly states that collective doses should not be used for epidemiological studies or for risk assessments because of large underlying biological and statistical uncertainties. ${ }^{14}$

This article received widespread publicity in the print and electronic media and raised a worldwide firestorm of controversy around radiation dose in diagnostic radiology. The ongoing CT multislice race which was leapfrogging from 64 to 256 to 320 and beyond was halted. Vendors turned their attention to reducing dose leading to several versions of iterative reconstruction algorithms and other strategies. The radiology fraternity in the United States was galvanized to audit practices countrywide and introduce initiatives for standardizing adult and pediatric CT protocols (Image Wisely and Image Gently respectively). Several articles in both AJR and Radiology between 2007 and 2011 addressed a whole gamut of issues ranging from technical aspects of CT dosimetry, risk assessment, and how radiologists could handle public concerns. ${ }^{16}$ Meanwhile, the validity of the LNT model was itself challenged with new evidence by a group of international experts. $^{17}$

Close on the heels of this upheaval, Pearce et al, in a retrospective study of children who had undergone CT scans of the head, observed that out of every 10,000 children followed over a 10 -year period, there was one excess case of brain tumor and one excess case of leukemia attributable to radiation. ${ }^{18}$ This widely cited study published in Lancet was later shown to have several serious methodological flaws. The individual doses were not recorded, and these doses were estimated from the make and model of the scanner. These were mostly adult doses from old generation scanners. Neither clinical indications for the scans nor the exposure from other investigations the child may have undergone were taken into consideration. Recent studies from France and Germany involving children who had undergone CT scans where the indications, family history, and predisposing conditions were factored in, found no excess risk of cancer in these children. ${ }^{19}$

\section{High Background Radiation Areas}

Biological effects of low dose radiation have been investigated by long-term observational studies of populations living in high background radiation areas (HBRAs). The coastal area in Karunagapally, Southern Kerala, has large deposits of thorium containing monazite sands and people living in the area are exposed to up to $70 \mathrm{mGy} / \mathrm{y}$ in some locations. The mean outdoor radiation levels are more than $4 \mathrm{mGy} / \mathrm{y}$. The outdoor and indoor doses of approximately 70,000 adult residents were recorded, and they were followed up for over 10 years. There was no increased incidence (excess risk) of cancer in this population compared with controls from nearby villages which were not HBRA. ${ }^{20}$ Similar studies from HBRA in China, Brazil and Iran have also shown no increased risk of cancer. $^{5}$

\section{Radiobiology, DNA Repair, Adaptive Response and Hormesis}

Since the body is $65 \%$ water and the DNA itself is compacted into a small part of the cell, direct "hit" by a photon is an exception rather than the rule. Most of the radiation damage is mediated through reactive oxygen species (RSOs) generated by hydrolysis of water molecules by the radiation. The subsequent injury is thus chemically mediated. The number of RSOs produced per day in a single human cell from normal metabolism has been estimated to be around 1 billion $\left(10^{9}\right)$ ! An efficient detoxifying system consisting of antioxidants, catalases, superoxide dismutase, etc., limits the number of DNA alterations to around one million $\left(10^{6}\right)$. DNA alterations can be single strand breaks, base change, or double strand breaks (DSBs). While single strand breaks and base changes are normally repaired efficiently within minutes, DSBs are uncommon, and the repair is more complex and carries the risk of lasting damage. In a normal nonradiated cell, DSBs have been estimated to occur at the rate of $0.1 /$ cell/d. A $1 \mathrm{mGy}$ dose to a mammalian cell has been estimated to produce only $5 \times 10^{-3}$ DNA alterations per cell compared with the huge $10^{6}$ changes occurring per day in a nonradiated cell. The dose of $1 \mathrm{mGy}$ is expected to produce only $1 / 1,000$ th number of DSBs compared with that produced by the normal endogenous metabolism. However, the proportion of DSB out of the total DNA alterations produced is 1,000 times more for ionizing radiation compared with endogenously induced DNA alterations. At high doses above $1 \mathrm{~Gy}$ the DSB proportion increases further and at lethal doses of $2.5 \mathrm{~Gy}$ and above it becomes the dominant effect causing widespread loss of cell function leading to the multiorgan failure of acute radiation syndrome. $^{21}$ 
DSB repair is activated within seconds of damage and is achieved by enzymes in the nucleus, triggered and orchestrated by several genes. One of the first steps in the DNA repair process is to pause the cell cycle. The DNA replication is prevented during repair. If the repair is not successful, the abnormal cell is eliminated by triggering an immune response or taking it down the senescence pathway or by apoptosis. It has been observed in humans and mice models that, after exposure to low dose radiation, the activated defense system remains upregulated for days or even weeks and responds with even greater efficiency to a subsequent exposure. This adaptive response has been shown to disappear at higher doses beyond $300 \mathrm{mGy}$ which indicates threshold dose response ( $\mathbf{- F i g . ~ 1 ) . ~}{ }^{17}$ Radiation hormesis is a related phenomenon whereby the repair systems primed by low dose radiation offers protection from all causes of DNA damage leading to a reduction in cancer risk compared with controls ${ }^{4,22}$ (-Fig. 1).

Life on earth originated approximately 2 billion years ago when the amount of radiation, both celestial and terrestrial, was much higher than it is today posing a permanent threat to nucleic acid stability. This accounts for the multi-pathway highly efficient mechanisms for RSO detoxification and DNA repair in all organisms ranging from the simplest unicellular yeast to the largest complex multicellular mammals. It has been said that the LNT model is based on a pure physical view of radiation effect on matter and does not make allowance for inherent DNA repair mechanisms in biological systems. ${ }^{5,22}$

\section{Lessons from Chernobyl and Fukushima and the Challenges of a Nuclear Renaissance}

The Chernobyl nuclear plant accident in 1986 is a worst-case scenario in which poor design and operator error combined to blow up the reactor operating under full power. The explosion was a result of high-pressure hydrogen gas build up within the reactor and its subsequent violent reaction with atmospheric oxygen. The hazards are primarily, heat and radiation from the exposed reactor and secondarily, fall out of the radioactive material released into the atmosphere. Twenty-eight plant personnel and first response fire fighters died from burns and acute radiation sickness. Radiation fall out exposed the evacuees in the neighborhood to a wholebody dose (cumulative over two decades) of $30 \mathrm{mSv}$. Though from one perspective this is equivalent to only couple of abdomen CT scans, it is 15 times the maximum permissible dose for public from a regulatory perspective in most countries. In the fall out zone outside this core area, the 20-year cumulative dose for an individual was $9 \mathrm{mSv}$. In the years that followed, approximately 15 excess deaths due to thyroid cancer in children were attributed to radioactive iodine $\left(\mathrm{I}^{131}\right)$ intake through milk. Large number of thyroid cancers detected in this period is believed to have been due to intensive screening and vast majority of them were successfully treated. No other excess cancer incidence or deaths have been observed so far. ${ }^{23}$ Contrary to the general perception of a "disaster" only approximately 40 to 50 deaths can be directly linked to the incident. On the other hand, the large-scale evacuation and resettlement that followed, produced loss of livelihood, disruption of social bonds, and profound psychological stress. More than 1,200 suicides were recorded in this displaced population. Moreover, thousands of pregnancies were voluntarily aborted in countries as far away as Greece though the dose from fall out in these locations was infinitesimally small. ${ }^{24}$

In 2011, the Fukushima nuclear plant in northern Japan was hit by a massive tsunami. Unlike Chernobyl, the reactor was shut down in time. However, the residual heat (decay heat) could not be cooled down since the back-up generators for the cooling system were flooded. Not a single person was killed or injured by radiation in the plant. The tsunami itself killed more than 18,000 people and resulted in extensive damage to homes and infrastructure. Panic and hurried evacuation of 100,000 people from a $20 \mathrm{~km}$ radius followed. The fallout from the reactors was widespread; but the exposure to individuals was not more than $2 \mathrm{mSv}$ in a year! Disruption of medication of chronically ill elderly people and accidents resulted in the deaths of at least 1,000 people during the evacuation. There has been no recorded incidence of excess cancer or any other health risks so far in this population which is being flowed up closely. ${ }^{25}$

Is it justifiable to risk the lives of hundreds of people now for a very small probability of reduced cancer in the distant future? What will be the incremental cost of reducing already low doses to negligible levels be it a CT or a nuclear plant? Is there any tangible benefit for such costs to patients and public? The average nonexpert anywhere in the world today continues to have the same fear of radiation engendered by the atom bomb in 1945 and this anxiety has been institutionalized by regulatory policy.

It has become imperative to rapidly reduce $\mathrm{CO}_{2}$ emissions to offset climate change. Nuclear power is being increasingly recognized as the cleanest source for base power which can be supplemented by solar, wind, and other renewable sources to achieve emission targets. Safety in nuclear installations is also anchored in the LNT model. Unlike thermal or hydel power, a large proportion of nuclear power costs goes into maintaining safety right from construction, to dedicated systems, and personnel during operation. A zero dose, absolute safety approach will make nuclear energy financially unviable, is not practically achievable and is not necessary if the LNT model is not valid for low doses. The " 15 country study," an almost 50 years follow up of over 400,000 nuclear plant workers, some of whom received up to $100 \mathrm{mSv}$ cumulative personal doses, in its final analysis, did not show any increased rate of cancer or any other deleterious effect. ${ }^{26,27}$

\section{Summary}

The LNT model was proposed and adopted in the 1950s based on early studies showing radiation-induced germline damage in fruit flies. The cancer data from the LSS was subsequently found to fit the model. Radiation safety concepts in the medical and nuclear industry are anchored in the LNT model. However, recent radiobiological studies and the 
long-term follow-up of the atom bomb survivors and other populations in HBRA seems to indicate that the cancer risk attributed to low dose radiation $(<100 \mathrm{mGy})$ maybe overestimated. The UNSCEAR, American Association of Physicists in Medicine and the French National Academy of sciences have affirmed that it is not possible to reliably attribute cancer risk to radiation doses below $100 \mathrm{mGy} .^{19,28}$

A very stringent application of the ALARA principle has unfortunately resulted in doctors and patients preferring MR over CT even when it is not appropriate. Moreover, body CT scan, especially in children, are many times uninterpretable due to image noise, defeating the very purpose of the scan. The most commonly performed radiological investigation with a relatively high dose is a multiphase abdomen MDCT. A recent study using 256 slice $\mathrm{CT}$ and model-based iterative reconstruction algorithm showed that the dose for a fourphase abdominal scan of good diagnostic quality was between 17 and $25 \mathrm{mSv}$ only. ${ }^{29}$

Adaptive response of the DNA repair systems can be expected to mitigate even repeated radiological exposures which are typically fractionated and cumulative over time. Acute patient doses in the $100 \mathrm{mSv}$ range are encountered only in complex interventional procedures. Current concepts can ameliorate some of the concerns of patients requiring such procedures. On the other hand, doses to IR personnel using appropriate protection gear and shielding are very low and any excess risk for cancer is very unlikely. Gonads are no longer considered the most radiosensitive organs and congenital anomalies or cancer in the next generation is extremely unlikely with doses in the diagnostic range. Similarly, for in utero exposure up to even $100 \mathrm{mSv}$, no anomalies or any other abnormality is expected over and above the normal incidence.

\section{Conclusion}

Limiting dose to patient will remain an important primary responsibility of the radiologist. However, as data from the LSS and other exposed populations around the world continues to accumulate, concepts will have to be continually reviewed and reshaped. Current state of evidence seems to indicate that doses below $100 \mathrm{mSv}$ have negligible or no risks. Based on a more realistic estimate of risk we could move from "as low as reasonably achievable" to a "as low as diagnostically acceptable" paradigm. Apart from adopting best practices and using advanced technology it has become imperative for radiologists to keep in touch with developments in this field so that we can continuously engage with the rest of the medical fraternity and public and assume our true roles as counsellors and guardians at the forefront of medical radiation safety. Meanwhile on the regulatory side, a "no safe dose" approach is convenient to frame policies and ensure compliance. But changes in regulatory policy concerning permissible doses could be expected in the future based on new evidence.

\section{Conflict of Interest}

None dseclared.

\section{References}

1 Brown P. American martyrs to radiology. Clarence Madison Dally (1865-1904). 1936. AJR Am J Roentgenol 1995;164(01):237-239

2 Muller HJ. Artificial transmutation of the gene. Science 1927;66 (1699):84-87

3 ICRP History Available from Accessed December 24, 2020 at: https://icrp.org/page.asp?id=210

4 Cuttler JM. What becomes of nuclear risk assessment in light of radiation hormesis? Dose Response 2006;5(01):80-90

5 Calabrese EJ, O'Connor MK. Estimating risk of low radiation doses -a critical review of the BEIR VII report and its use of the linear no-threshold (LNT) hypothesis. Radiat Res 2014;182(05): 463-474

6 ICRP, 1977. Recommendations of the ICRP. ICRP Publication 26 1977 Ann. ICRP 1 (3)

7 Douple EB, Mabuchi K, Cullings HM, et al. Long-term radiationrelated health effects in a unique human population: lessons learned from the atomic bomb survivors of Hiroshima and Nagasaki. Disaster Med Public Health Prep 2011;5(Suppl 1): S122-S133

8 Grant EJ, Brenner A, Sugiyama $\mathrm{H}$, et al. Solid cancer incidence among the life span study of atomic bomb survivors: 1958-2009. Radiat Res 2017;187(05):513-537

9 Ozasa K, Grant EJ, Kodama K. Japanese legacy cohorts: the life span study atomic bomb survivor cohort and survivors' offspring. J Epidemiol 2018;28(04):162-169

10 Jordan BR. The Hiroshima/Nagasaki survivor studies: discrepancies between results and general perception. Genetics 2016;203 (04):1505-1512

11 NCR. Health Risks from Exposures to Low Levels of Ionizing Radiation: BEIR VII Phase 2. National Research Council, Washington DC: National Academy Press; 2006

12 Hendee WR, O'Connor MK. Radiation risks of medical imaging: separating fact from fantasy. Radiology 2012;264(02): 312-321

13 Pregnancy and Medical Radiation. ICRP Publication 84. 2000; Ann ICRP;30(1)

14 Recommendations of the International Commission on Radiological Protection. ICRP Publication 103. 2007 Ann. ICRP 37 (2-4)

15 Brenner DJ, Hall EJ. Computed tomography-an increasing source of radiation exposure. N Engl J Med 2007;357(22):2277-2284

16 Hricak H, Brenner DJ, Adelstein SJ, et al. Managing radiation use in medical imaging: a multifaceted challenge. Radiology 2011;258 (03):889-905

17 Tubiana M, Feinendegen LE, Yang C, Kaminski JM. The linear nothreshold relationship is inconsistent with radiation biologic and experimental data. Radiology 2009;251(01):13-22

18 Pearce MS, Salotti JA, Little MP, et al. Radiation exposure from CT scans in childhood and subsequent risk of leukaemia and brain tumours: a retrospective cohort study. Lancet 2012;380 (9840):499-505

19 McCollough CH, Bushberg JT, Fletcher JG, Eckel LJ. Answers to common questions about the use and safety of CT scans. Mayo Clin Proc 2015;90(10):1380-1392

20 Nair RR, Rajan B, Akiba S, et al. Background radiation and cancer incidence in Kerala, India-Karanagappally cohort study. Health Phys 2009;96(01):55-66

21 Pollycove M, Feinendegen LE. Radiation-induced versus endogenous DNA damage: possible effect of inducible protective responses in mitigating endogenous damage. Hum Exp Toxicol 2003;22(06):290-306, discussion 307, 315-317, 319-323

22 Calabrese EJ, Baldwin LA. Toxicology rethinks its central belief. Nature 2003;421(6924):691-692

23 United Nations Scientific Committee on the Effects of Atomic Radiation (UNSCEAR) 2008. Sources and effects of ionizing radiation. Vol. II, Scientific Annex D: Health effects due to radiation from the Chernobyl accident. Accessed December 24, 2020 at: https://www. 
unsear.org/docs/publications/2008/UNSCEAR_2008_Annexe-DCORR.pdf

24 Wigg DR. Radiation: facts, fallacies and phobias. Australas Radiol 2007;51(01):21-25

25 United Nations Scientific Committee on the Effects of Atomic Radiation (UNSCEAR) 2013Sources, effects and risks of ionizing radiation. Vol I Scientific AnnexA: levels and effects of radiation exposure due to the nuclear accident after the 2011 Great East Japan earthquake and tsunami. Accessed December 24, 2020 at: https://www.unsear.org/docs/reports/2013/13-85418_Report_2013_Annexe_A.pdf

26 Cardis E, Vrijheid M, Blettner M, et al. Risk of cancer after low doses of ionising radiation: retrospective cohort study in 15 countries. BMJ 2005;331(7508):77
27 Zablotska LB, Lane RS, Thompson PA. A reanalysis of cancer mortality in Canadian nuclear workers (1956-1994) based on revised exposure and cohort data. Br J Cancer 2014;110(01): 214-223

28 Tubiana M, Aurengo A, Averbeck D, et al, eds. Dose-Effect Relationships and the Estimation of the Carcinogenic Effects of Low Doses of Ionizing Radiation. Academy of Medicine (Paris) and Academy of Science (Paris) Joint Report No. 2, March 30; 2005

29 Kulkarni CB, Pullara SK, Prabhu NK, Patel S, Suresh A, Moorthy S. Comparison of knowledge-based iterative model reconstruction (IMR) with hybrid iterative reconstruction (iDose $\mathrm{i}^{4}$ ) techniques for evaluation of hepatocellular carcinomas using computed tomography. Acad Radiol 2020;S1076-6332(20):30483-30489 